\title{
Gabapentin versus baclofen for treatment of refractory gastroesophageal reflux-induced chronic cough
}

\author{
Mengru Zhang, Yiqing Zhu, Ran Dong, Zhongmin Qiu \\ Department of Pulmonary and Critical Care Medicine, Tongji Hospital, Tongji University School of Medicine, Shanghai, China \\ Contributions: (I) Conception and design: Z Qiu; (II) Administrative support: Z Qiu; (III) Provision of study materials or patients: M Zhang, R Dong; \\ (IV) Collection and assembly of data: M Zhang, Y Zhu; (V) Data analysis and interpretation: All authors; (VI) Manuscript writing: All authors; (VII) \\ Final approval of manuscript: All authors. \\ Correspondence to: Dr. Zhongmin Qiu. Department of Pulmonary and Critical Care Medicine, Tongji Hospital, Tongji University School of Medicine, \\ No. 389 Xincun Road, Shanghai, China. Email: qiuzhongmin@tongji.edu.cn.
}

\begin{abstract}
Refractory gastroesophageal reflux-induced chronic cough (GERC) is a special type of gastroesophageal reflux disease (GERD) with predominant cough resistant to pragmatic standard antireflux therapy including antisecretory agents alone or in combination with promotility agents but with a favorable response to intensified anti-reflux treatment. The condition is not rare and is difficult to treat. Neuromodulators such as baclofen and gabapentin are considered potential therapeutic options for refractory GERC. Limited data indicate that gabapentin and baclofen could attenuate the cough symptom in patients with refractory GERC by blockade of gastroesophageal reflux or by direct antitussive effects. However, no study has compared the efficacy of these two drugs in treatment of refractory GERC. In an open-labeled randomized clinical study, we demonstrated that, as add-on therapy, gabapentin and baclofen had a similar prevalence of therapeutic success for suspected refractory GERC but gabapentin may be more preferable because of its fewer central side effects. The efficacy of baclofen and gabapentin was suboptimal, so further studies are needed to select the patients with refractory GERC suitable for precise treatment using these two neuromodulators.
\end{abstract}

Keywords: Baclofen; chronic cough; gabapentin; gastroesophageal reflux; neuromodulators

Submitted Feb 25, 2020. Accepted for publication Aug 10, 2020.

doi: $10.21037 /$ jtd-2020-icc-002

View this article at: http://dx.doi.org/10.21037/jtd-2020-icc-002

\section{Introduction}

As a common extraesophageal symptom, cough occurs in $30.5-34.9 \%$ patients with gastroesophageal reflux disease (GERD) (1). Gastroesophageal reflux-induced chronic cough (GERC) is a special type of GERD manifested by a prominent cough symptom (2) and is one of the important etiologies of chronic cough (2-4). Like GERD, antireflux drugs used for the treatment of GERC include antiacid agents and promotility agents which decrease the acidity of refluxates in the former and promote esophageal clearance or gastric emptying in the latter respectively (2). Therefore, in addition to lifestyle modification, pragmatic standard medical therapy for GERC can be antisecretory agents such as proton pump inhibitors (PPIs) and $\mathrm{H} 2$ antagonists alone or in combination with promotility agents though the therapeutic efficacy of PPIs is controversial $(5,6)$. Nevertheless, more than one-third patients with GERC fail to respond to the pragmatic standard medical therapy stated above (7): these patients can be said to be suffering from "refractory GERC" (8). The latter is difficult to treat and remains a major unmet clinical need.

\section{Defining refractory GERC}

There is no established consensus regarding how to define refractory GERC in terms of therapy duration and degree of therapeutic response. The current definition of GERC is 
derived mostly from that of "refractory GERD". GERD is diagnosed and treated in clinical practice based on symptom assessment. Hence, in general, refractory GERD is defined as persistent classical reflux-related symptoms (regurgitation and/or heartburn) unresponsive to treatment with PPIs twice-daily for at least 4-8 weeks (9). Recently, the trend for gastroenterologists has been to accept refractory GERD as a condition in which patients continue to report bothersome symptoms despite treatment for $\geq 12$ weeks with a stable double dose of PPIs $(10,11)$. Considering cough can be induced by many diseases other than GERC, its causeeffect association with reflux is more difficult to establish than that for regurgitation and heartburn. Also, excessively long trials with antisecretory therapy for GERC may delay management of the other causes of chronic cough.

We have defined refractory GERC as an entity of chronic cough with the objective evidence of abnormal reflux as identified by multiple-channel intraluminal impedance$\mathrm{pH}$ monitoring (MII-pH) which is resistant to an 8-week pragmatic medical anti-reflux therapy consisting of PPIs twice daily and promotility agents but responds favorably to intensified anti-reflux therapy which includes higher doses of PPIs or add-on therapies with histamine $\mathrm{H} 2$ receptor antagonists and neuromodulators, and finally leads to cough resolution (8). This definition is in accordance with the principles recommended in several guidelines for the management of chronic cough $(2,5,6,12)$ as well as general knowledge of refractory GERD $(10,11)$, but separates it from chronic refractory cough in that reflux is definitely identified as the cause of cough $(6,12)$.

\section{Neuromodulators for treatment of refractory GERC}

The mechanisms underlying refractory GERC are poorly understood. They may be associated with inadequate suppression of acids, non-acid reflux, transient lower esophageal sphincter relaxations (TLESRs) and esophageal or cough hypersensitivity (8). To target these pathophysiologic mechanisms, the theoretical therapeutic options available for refractory GERC are optimization of acid suppression, promotility agents, and anti-reflux surgery because they can all reduce the frequency of reflux or volume of refluxate (8). Hence, they relieve cough by inhibiting micro-aspiration of the refluxate into the airways and esophageal-tracheobronchial reflexes (2). However, complete suppression of acid achieved by a high dose of PPIs has limited therapeutic gain unless patients with chronic cough present with evidence of pathologic exposure to esophageal acid (13). Also, the benefit of promotility agents has not been ascertained (14). In addition, antireflux surgery is employed in only a small fraction of eligible patients even though it is an efficacious alternative to medications in patients with proven GERC (15). Neuromodulators have been identified as promising treatment for chronic refractory cough (16), so they are also considered as a potential therapeutic option for refractory GERC. Among the neuromodulators available, only baclofen and gabapentin have been used for treatment of refractory GERC.

\section{Baclofen for refractory GERC}

Baclofen is an agonist of the $\gamma$-aminobutyric acid (GABA) type-B receptor. Traditionally, it has been used to treat spastic muscle disorders but has also been employed for treatment of refractory GERD (10). The main rationale is that baclofen modulates TLESRs mediated by vagal-reflex pathways through activation of GABA type-B receptors (17). TLESRs account for the vast majority of reflux events, so baclofen may be helpful against refractory GERD through inhibition of both acid reflux and nonacid reflux (18). Studies with limited sample sizes have shown that baclofen decreased the prevalence of TLESRs by $40-60 \%$ and the prevalence of episodes of acid reflux or non-acid reflux by $43 \%(17,19,20)$. Vela and colleagues illustrated that baclofen reduced the prevalence of symptoms related to acid reflux by $72 \%$ and those related to non-acid reflux by $21 \%$ in a small cohort of patients with heartburn (21). A meta-analysis involving nine RCTs with a total of 283 GERD patients and healthy volunteers concluded that baclofen reduced the prevalence of GERD, exposure time to esophageal acid, and TLESRs, though the studies were not limited to co-therapy with PPIs (22).

In addition to inhibition of TLESRs, baclofen has nonspecific antitussive activity in animals (23) and humans $(24,25)$. Several lines of evidence have shown that baclofen is helpful for the cough caused by angiotensin-converting enzyme inhibitors (26) and chronic refractory cough of unknown cause (27). Based on such observations, we tried to include baclofen in an intensified anti-reflux regimen as add-on therapy to antisecretory drugs to treat suspected refractory GERC. In a case report, we first demonstrated that cough was resolved in three patients with GERC in response to baclofen treatment (28). The subsequent prospective and open interventional clinical 
trial demonstrated that baclofen could eliminate or substantially improve cough symptoms and reduce the cough sensitivity to inhaled capsaicin in $56.3 \%(9 / 16)$ of patients with suspected refractory GERC (29). As a final step of a sequential stepwise anti-reflux strategy, the final escalation to baclofen yielded a favorable response in an additional 38 patients resistant to previous two-step trials of high-dose omeprazole and in combination with ranitidine, and achieved a successful outcome in $36.9 \%$ of 103 patients recruited for suspected refractory GERC (7). Therefore, baclofen may be a viable option for refractory GERC unresponsive to pragmatic standard medical anti-reflux therapy.

Baclofen reduces but does not completely abolish TLESRs. Thus, residual reflux may continue to produce cough through stimulation of the receptors in the esophageal mucosa (8). Furthermore, some ongoing refluxes may be secondary to the narrowed pressure difference between the stomach and esophagus, which is unrelated to TLESRs. This is why baclofen is not always efficacious in treatment of refractory GERC.

The main side effects of baclofen are associated with the central nervous system because it crosses the blood-brain barrier. Many patients experience somnolence, dizziness and drowsiness despite progressive titration of the drug from 5 to $20 \mathrm{mg}$ over 1 to 2 weeks. Nevertheless, such drug-related somnolence, drowsiness and fatigue are usually tolerable and may wane within 3 weeks in most patients $(6,28)$. Only a few patients have to discontinue baclofen treatment due to severe dizziness and drowsiness (29).

\section{Gabapentin for refractory GERC}

Gabapentin is a chemical analog of GABA. It combines specifically with the $\alpha_{2} \delta$ subunit of intracranial voltagegated calcium channels to block neurotransmitter release in synapses. Gabapentin was developed originally for epilepsy treatment and was also claimed to be beneficial against anxiety, bipolar disorder, and hot flashes (30). Gabapentin has been found to ameliorate chronic neuropathic pain, which is associated with central sensitization (31). Neuropathic pain and chronic cough are believed to share similar pathophysiologic mechanisms. Thus, gabapentin is considered to be a potential non-specific antitussive for chronic refractory cough through possible inhibition of a sensitized cough center.

The first clinical observation of gabapentin involved
28 patients who had chronic refractory cough related to laryngeal sensory neuropathy. They were treated with gabapentin (100-900 mg/day) and cough relief was achieved in $68 \%$ of patients (32). A subsequent case report showed that gabapentin completely resolved or substantially improved symptoms in $5 / 6$ patients with chronic refractory cough of unknown cause (33). In a placebocontrolled, double-blind clinical trial, Ryan and colleagues demonstrated that gabapentin, if increased gradually from 300 to $1,800 \mathrm{mg} /$ day, alleviated the symptoms and improved the quality of life of patients with chronic refractory cough significantly at 8 weeks of treatment (34). They also observed that patients presenting with symptoms of central sensitization (as reflected by laryngeal paraesthesia, allotussia and hypertussia) had an enhanced response to gabapentin treatment (34). A meta-analysis of seven relevant articles (including two randomized controlled trials) provided further support for the notion that gabapentin treatment is efficacious and safe in patients with chronic refractory cough (35).

Similar to baclofen, gabapentin mainly has central nervous system-related side effects. Confusion, dizziness and fatigue may occur in $12-18 \%$ patients receiving the therapy with gabapentin (34). The progressive titration or temporary reduction of the drug dose improves the tolerance of the patients to gabapentin (34).

Surprisingly, few scholars have evaluated the efficacy of gabapentin for treatment of refractory GERC despite the relatively abundant clinical trials focusing on the effects of gabapentin in patients with chronic refractory cough. Madanick and colleagues reported that, as addon therapy, gabapentin was efficacious in $~ 75 \%$ of patients with suspected GERC, which resulted in $\geq 50 \%$ subjective improvement in cough irrespective of findings of esophageal $\mathrm{pH}$ (36). The gabapentin dose administered was obviously lower than that employed by Ryan and colleagues, starting at $100 \mathrm{mg} /$ day and titrating up to $300 \mathrm{mg} /$ day in most patients and as high as $\geq 900 \mathrm{mg} /$ day in a few patients (36). Nevertheless, Madanick and colleagues did not recruit specifically patients with GERC resistant to pragmatic medical therapy (e.g., PPIs). This omission could explain the exceptionally high prevalence of success of gabapentin in their patient cohort because the effects of antisecretory agents might be sufficient and addition of gabapentin was not needed for cough resolution in several patients. Whether patients with refractory GERC benefit from gabapentin therapy is an interesting clinical issue. 
Table 1 General information of the patients with suspected refractory gastroesophageal reflux-induced chronic cough assigned to gabapentin group or baclofen group (mean $\pm \mathrm{SD})$

\begin{tabular}{|c|c|c|}
\hline Variables & Gabapentin group $(n=117)$ & Baclofen group $(n=117)$ \\
\hline Ages (year) & $47.5 \pm 10.1$ & $45.2 \pm 14.3$ \\
\hline Cough persistence (month) & $6.5(23.0)$ & $7.5(25.5)$ \\
\hline BMI $\left(\mathrm{kg} / \mathrm{m}^{2}\right)$ & $24.9 \pm 3.1$ & $24.2 \pm 2.5$ \\
\hline FVC (\% predictive value) & $97.2 \pm 12.6$ & $98.1 \pm 13.9$ \\
\hline FEV1/FVC (\%) & $80.9 \pm 9.3$ & $81.8 \pm 12.7$ \\
\hline Positive histamine bronchial provocation (n, \%) & $13(11.1)$ & $17(14.5)$ \\
\hline FeNO $\geq 25 \mathrm{ppb}(\mathrm{n}, \%)$ & $22(18.8)$ & $15(12.8)$ \\
\hline SAP for acid reflux (\%) & $5.4(75.3)$ & $10.1(81.9)$ \\
\hline SAP for nonacid reflux (\%) & $21.8(68.3)$ & $31.9(50.2)$ \\
\hline
\end{tabular}

Data on cough persistence, SAP for acid reflux and SAP for nonacid reflux are presented as medians (25-75\% interquartile). The table is adapted from (37). Eos, eosinophils; FeNO, fractional exhaled nitric oxide; FEV1, forced expiratory volume in one second; FVC, forced vital capacity; SAP, symptom association probability.

\section{Comparison between gabapentin and baclofen for treatment of refractory GERC}

Despite the clinical use of baclofen and gabapentin, scholars have not compared the efficacy of these two neuromodulators for treatment of refractory GERC. Thus, we undertook an open-labeled randomized clinical investigation to try to clarify the issue (37).

A total of 234 patients with suspected refractory GERC were enrolled into the study, and their demographic characteristics are shown in Table 1 (37). Before the diagnosis of possible GERC, the other causes of chronic cough (e.g., cough-variant asthma) were excluded by the negative findings of laboratory work-up and therapeutic trials specific to these causes. Objective evidence of abnormal reflux was documented by a positive DeMeester score $(\geq 14.72)$ and symptom association probability $(\geq 95 \%)$ as revealed by MII-pH. Refractory GERC was considered if an 8-week course of treatment with omeprazole and domperidone failed to attenuate cough. The subjective measures of cough severity (cough symptom score) and cough sensitivity to inhaled capsaicin were taken before and after treatment in adult participants assigned randomly to treatment with gabapentin (maximum daily dose of $900 \mathrm{mg}$ ) or baclofen (maximum daily dose of $60 \mathrm{mg}$ ) over 12 weeks as add-on therapy to previous anti-reflux treatment (Table 2).

The two participant groups were closely matched before treatment allocation (37). Gabapentin showed a similar prevalence of success for cough resolution to that of baclofen (57.3\% vs. 53.0\%) (Figure 1) and achieved comparable improvement in cough severity, cough sensitivity to capsaicin and the other symptoms related to reflux in terms of a questionnaire on GERD (Table 3). However, the prevalence of somnolence $(20.5 \%$ vs. $35.0 \%$, $\mathrm{P}=0.013)$ and dizziness $(11.1 \%$ vs. $23.9 \%, \mathrm{P}=0.010)$ was significantly lower in the gabapentin group than in the baclofen group (37).

Based on the mechanisms underlying gastroesophageal reflux and the blockade of TLESRs by baclofen, we speculated that baclofen would be superior to gabapentin for treatment of refractory GERC at this stage of the study design even though both have nonspecific central antitussive action (Figure 2). Unfortunately, the final results of comparable therapeutic efficacy between gabapentin and baclofen failed to confirm our hypothesis. Actually, gabapentin might have superiority over baclofen because 
Table 2 Scheduling doses of baclofen and gabapentin in refractory gastroesophageal reflux-induced chronic cough

\begin{tabular}{llll}
\hline Drug & Phase & Day & Dose \\
\hline Baclofen & Escalation & $1-9$ & Initially $30 \mathrm{mg} / \mathrm{d}$, then an increase of extra $10 \mathrm{mg} / \mathrm{d}$ every three days \\
& Maximal treatment & $10-66$ & $60 \mathrm{mg} / \mathrm{d}(20 \mathrm{mg}$, three times daily) \\
& Reduction & $67-87$ & A decrease of $30 \mathrm{mg} / \mathrm{d}$ in first week, then a decrease of $10 \mathrm{mg} / \mathrm{d}$ a week \\
Gabapentin & Escalation & $1-6$ & Initially $100 \mathrm{mg} /$ time, three times daily, then an increase of extra $100 \mathrm{mg} / \mathrm{time}$ every three days \\
& Maximal treatment & $7-63$ & $900 \mathrm{mg} / \mathrm{d}(300 \mathrm{mg}$, three times daily) \\
& Reduction & $64-74$ & A decrease of $100 \mathrm{mg} /$ time a week \\
\hline
\end{tabular}

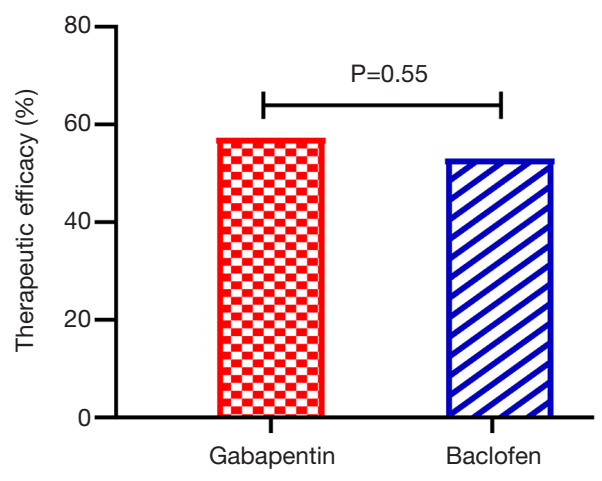

Figure 1 Comparison of overall therapeutic success between gabapentin and baclofen during treatment of suspected refractory gastroesophageal reflux-induced chronic cough. the gabapentin dose could be increased to a maximum of 1,800 mg daily as used by Ryan and colleagues (34), which was double the dose utilized in our study. Therefore, our findings may reflect the true efficacy of the two drugs for the management of suspected refractory GERC.

Gabapentin attenuates cough mainly through inhibition of the hypersensitive cough center just as it relaxes the neuropathic pain by suppressing central hyperalgesia (38). At present, gabapentin has no proven direct anti-reflux effects even though the cough resolution by gabapentin and baclofen is expected to reduce the number of reflux episodes by interrupting the self-perpetuating "vicious cycle" of reflux and cough (39). Our study suggests that central cough hypersensitivity is as important as TLESRs during

Table 3 Comparison of variables between the gabapentin group and baclofen group

\begin{tabular}{|c|c|c|c|c|}
\hline Variable & \multicolumn{2}{|c|}{ Gabapentin group $(n=111)$} & \multicolumn{2}{|c|}{ Baclofen group ( $n=106)$} \\
\hline \multicolumn{5}{|c|}{ Cough symptom score } \\
\hline Daytime & $3.1 \pm 0.5$ & $0.7 \pm 0.5^{\star}$ & $2.9 \pm 0.5$ & $0.7 \pm 0.4^{*}$ \\
\hline Nighttime & $1.8 \pm 0.9$ & $0.2 \pm 0.5^{\star}$ & $1.6 \pm 0.5$ & $0.2 \pm 0.4^{*}$ \\
\hline $\mathrm{C} 2(\mu \mathrm{mol} / \mathrm{L})$ & $1.1 \pm 0.3$ & $3.6 \pm 0.8^{\star}$ & $1.4 \pm 0.5$ & $4.5 \pm 1.5^{\star}$ \\
\hline $\mathrm{C} 5(\mu \mathrm{mol} / \mathrm{L})$ & $2.1 \pm 0.7$ & $9.5 \pm 1.5^{\star}$ & $3.5 \pm 0.9$ & $11.2 \pm 3.4^{*}$ \\
\hline GerdQ score & $8.8 \pm 2.4$ & $7.4 \pm 1.5^{\star}$ & $9.1 \pm 2.8$ & $7.4 \pm 1.9^{\star}$ \\
\hline
\end{tabular}

Data are the mean $\pm \mathrm{SD},{ }^{*}, \mathrm{P}<0.05$ compared with baseline. GerdQ, gastroesophageal reflux disease questionnaire. 


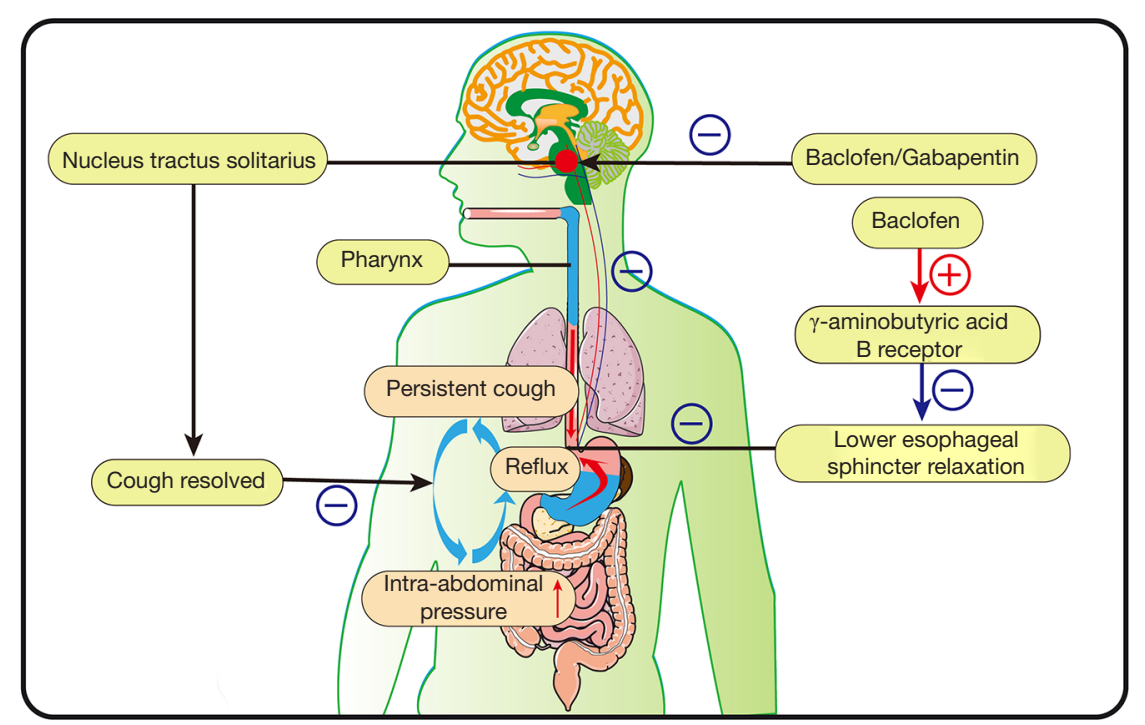

Figure 2 Possible action mechanisms of baclofen and gabapentin in the treatment of refractory gastroesophageal reflux-induced chronic cough. Baclofen inhibits acid reflux as well as nonacid reflux by modulating transient lower esophageal sphincter relaxations; both baclofen and gabapentin have nonspecific central antitussive effect by acting hypersensitive cough center (nucleus tractus solitarius),which then may further suppress both acid reflux and nonacid reflux by interrupting the self-perpetuating "vicious cycle" of reflux and cough.

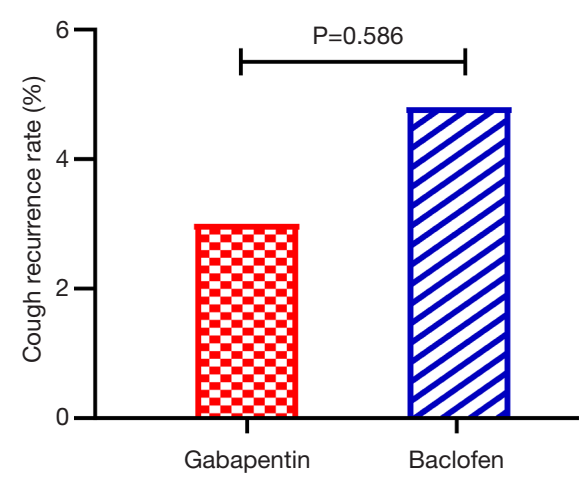

Figure 3 Comparison of the prevalence of cough recurrence between the gabapentin group and baclofen group after 2 weeks of complete withdrawal of treatment of the two neuromodulators.

the pathogenesis of refractory GERC.

Cough resolution was sustained in responders during an 8 -week course of treatment with gabapentin or baclofen and the subsequent 3 -week dose-reduction schedule. In chronic refractory cough, the therapeutic effects of neuromodulators are not maintained after treatment cessation (34). However, in our study, only a few patients had a relapse of cough after 2 weeks of complete withdrawal of gabapentin or baclofen, and there was no difference in the prevalence of recurrence between the two groups (Figure 3). However, 6 months later, cough recurred in almost all patients. The delayed recurrence of cough following cessation of treatment of baclofen/gabapentin and temporary maintenance of cough resolution might have been due to subsequent continuance of standard anti-reflux therapy comprising omeprazole and domperidone.

The efficacy of baclofen and gabapentin was suboptimal because $>40 \%$ patients with refractory GERC did not respond to these neuromodulators. Such benefit in only a subset of patients may suggest the heterogeneity of refractory GERC and the limitation of these two neuromodulators as add-on therapy. However, we think that baclofen and gabapentin, even though they are imperfect, should be used in patients with refractory GERC. Considering the severe negative impact of refractory cough on quality of life, cough resolution (even in a few patients) can be considered to be successful and important in clinical practice.

\section{Conclusions}

Refractory GERC is difficult to manage. In addition to optimization of acid suppression and anti-reflux surgery, neuromodulators such as gabapentin and 
baclofen have a place in the management of refractory GERC. Limited evidence supports their use because the two drugs ameliorate chronic refractory cough due to gastroesophageal reflux. We demonstrated that as add-on therapy, gabapentin and baclofen had a similar prevalence of therapeutic success for suspected refractory GERC, but that gabapentin may be more preferable because of the fewer central side effects it elicits (37). However, the efficacy of baclofen and gabapentin was suboptimal, and $>40 \%$ of patients with suspected refractory GERC failed to respond to therapy with these two drugs. The future direction for research should be focused on how to screen patients with refractory GERC suitable for therapy using gabapentin or baclofen, to improve therapeutic efficacy, and avoid the unnecessary adverse effects.

\section{Acknowledgments}

Funding: This study was supported in part by grants from the National Natural Science Foundation of China (No. 81670092, 81470276) and Tongji Hospital (TJ1801).

\section{Footnote}

Provenance and Peer Review: This article was commissioned by the Guest Editor (Kefang Lai) for the series " $3 \mathrm{rd}$ International Cough Conference" published in fournal of Thoracic Disease. The article was sent for external peer review organized by the Guest Editor and the editorial office.

Conflicts of Interest: All authors have completed the ICMJE uniform disclosure form (available at http:// dx.doi.org/10.21037/jtd-2020-icc-002). The series "3rd International Cough Conference" was commissioned by the editorial office without any funding or sponsorship. The authors have no other conflicts of interest to declare.

Ethical Statement: The authors are accountable for all aspects of the work in ensuring that questions related to the accuracy or integrity of any part of the work are appropriately investigated and resolved.

Open Access Statement: This is an Open Access article distributed in accordance with the Creative Commons Attribution-NonCommercial-NoDerivs 4.0 International License (CC BY-NC-ND 4.0), which permits the noncommercial replication and distribution of the article with the strict proviso that no changes or edits are made and the original work is properly cited (including links to both the formal publication through the relevant DOI and the license). See: https://creativecommons.org/licenses/by-nc-nd/4.0/.

\section{References}

1. Jaspersen D, Kulig M, Labenz J, et al. Prevalence of extraoesophageal manifestations in gastro-oesophageal reflux disease: an analysis based on the ProGERD Study. Aliment Pharmacol Ther 2003;17:1515-20.

2. Irwin RS. Chronic cough due to gastroesophageal reflux disease: ACCP evidence-based clinical practice guidelines. Chest 2006;129:80S-94S.

3. Lai K, Chen R, Lin J, et al. A prospective, multicenter survey on causes of chronic cough in China. Chest 2013;143:613-20.

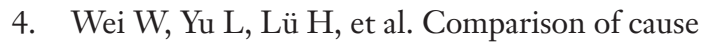
distribution between elderly and non-elderly patients with chronic cough. Respiration 2009;77:259-64.

5. Kahrilas PJ, Altman KW, Chang AB, et al. Chronic cough due to gastroesophageal reflux in adults: CHEST Guideline and Expert Panel Report. Chest 2016;150:1341-60.

6. Morice AH, Millqvist E, Bieksiene $\mathrm{K}$, et al. ERS guidelines on the diagnosis and treatment of chronic cough in adults and children. Eur Respir J 2020;55:1901136.

7. Xu X, Lv H, Yu L, et al. A stepwise protocol for the treatment of refractory gastroesophageal reflux-induced chronic cough. J Thorac Dis 2016;8:178-85.

8. Lv HJ, Qiu ZM. Refractory chronic cough due to gastroesophageal reflux: definition, mechanism and management. World J Methodol 2015;5:149-56.

9. Liu JJ, Saltzman JR. Refractory gastro-oesophageal reflux disease: diagnosis and management. Drugs 2009;69:1935-44.

10. Sifrim D, Zerbib F. Diagnosis and management of patients with reflux symptoms refractory to proton pump inhibitors. Gut 2012;61:1340-54.

11. Gyawali CP, Kahrilas PJ, Savarino E, et al. Modern diagnosis of GERD: the Lyon Consensus. Gut 2018;67:1351-62.

12. Lai K, Shen H, Zhou X, et al. Clinical Practice guidelines for diagnosis and management of cough - Chinese Thoracic Society (CTS) Asthma Consortium. J Thorac Dis 2018;10:6314-51.

13. Kahrilas PJ, Howden CW, Hughes N, et al. Response of chronic cough to acid-suppressive therapy in patients with 
gastroesophageal reflux disease. Chest 2013;143:605-12.

14. Hillman L, Yadlapati R, Thuluvath AJ, et al. A review of medical therapy for proton pump inhibitor nonresponsive gastroesophageal reflux disease. Dis Esophagus 2017;30:1-15.

15. Schwameis K, Oh D, Green KM, et al. Clinical outcome after laparoscopic Nissen fundoplication in patients with GERD and PPI refractory heartburn. Dis Esophagus 2020;33:doz099.

16. Wei $\mathrm{W}$, Liu R, ZhangTong $\mathrm{Y}$, et al. The efficacy of specific neuromodulators on human refractory chronic cough: a systematic review and meta-analysis. J Thorac Dis 2016;8:2942-51.

17. Zhang Q, Lehmann A, Rigda R, et al. Control of transient lower oesophageal sphincter relaxations and reflux by the GABA(B) agonist baclofen in patients with gastrooesophageal reflux disease. Gut 2002;50:19-24.

18. Boeckxstaens GE. Reflux inhibitors: a new approach for GERD? Curr Opin Pharmacol 2008;8:685-9.

19. Beaumont H, Boeckxstaens GE. Does the presence of a hiatal hernia affect the efficacy of the reflux inhibitor baclofen during add-on therapy? Am J Gastroenterol 2009;104:1764-71.

20. Lidums I, Lehmann A, Checklin H, et al. Control of transient lower esophageal sphincter relaxations and reflux by the GABA (B) agonist baclofen in normal subjects. Gastroenterology 2000;118:7-13.

21. Vela MF, Tutuian R, Katz PO, et al. Baclofen decreases acid and non-acid post-prandial gastroesophageal reflux measured by combined multichannel intraluminal impedance and $\mathrm{pH}$. Aliment Pharmacol Ther 2003;17:243-51.

22. Li S, Shi S, Chen F, et al. The effects of baclofen for the treatment of gastroesophageal reflux disease: a metaanalysis of randomized controlled trials. Gastroenterol Res Pract 2014;2014:307805.

23. Bolser DC, Aziz SM, DeGennaro FC, et al. Antitussive effects of GABAB agonists in the cat and guinea-pig. Br J Pharmacol 1993;110:491-5.

24. Dicpinigaitis PV, Dobkin JB. Antitussive effect of the GABA-agonist baclofen. Chest 1997;111:996-9.

25. Dicpinigaitis PV, Dobkin JB, Rauf K, et al. Inhibition of

Cite this article as: Zhang M, Zhu Y, Dong R, Qiu Z. Gabapentin versus baclofen for treatment of refractory gastroesophageal reflux-induced chronic cough. J Thorac Dis 2020;12(9):5243-5250. doi: 10.21037/jtd-2020-icc-002 capsaicin-induced cough by the gamma-aminobutyric acid agonist baclofen. J Clin Pharmacol 1998;38:364-7.

26. Dicpinigaitis PV. Use of baclofen to suppress cough induced by angiotensin-converting enzyme inhibitors. Ann Pharmacother 1996;30:1242-5.

27. Dicpinigaitis PV, Rauf K. Treatment of chronic, refractory cough with baclofen. Respiration 1998;65:86-8.

28. Xu X, Chen Q, Liang S, et al. Successful resolution of refractory chronic cough induced by gastroesophageal reflux with treatment of baclofen. Cough 2012;8:8.

29. Xu XH, Yang ZM, Chen Q, et al. Therapeutic efficacy of baclofen in refractory gastroesophageal reflux-induced chronic cough. World J Gastroenterol 2013;19:4386-92.

30. Cheng JK, Chiou LC. Mechanisms of the antinociceptive action of gabapentin. J Pharmacol Sci 2006;100:471-86.

31. Kimos P, Biggs C, Mah J, et al. Analgesic action of gabapentin on chronic pain in the masticatory muscles: a randomized controlled trial. Pain 2007;127:151-60.

32. Lee B, Woo P. Chronic cough as a sign of laryngeal sensory neuropathy: diagnosis and treatment. Ann Otol Rhinol Laryngol 2005;114:253-7.

33. Mintz S, Lee JK. Gabapentin in the treatment of intractable idiopathic chronic cough: case reports. Am J Med 2006;119:e13-5.

34. Ryan NM, Birring SS, Gibson PG. Gabapentin for refractory chronic cough: a randomised, double-blind, placebo-controlled trial. Lancet 2012;380:1583-9.

35. Shi G, Shen Q, Zhang C, et al. Efficacy and safety of gabapentin in the treatment of chronic cough: a systematic review. Tuberc Respir Dis (Seoul) 2018;81:167-74.

36. Madanick RD. Management of GERD-related chronic cough. Gastroenterol Hepatol (N Y) 2013;9:311-3.

37. Dong R, Xu X, Yu L, et al. Randomised clinical trial: gabapentin vs. baclofen in the treatment of suspected refractory gastro-oesophageal reflux-induced chronic cough. Aliment Pharmacol Ther 2019;49:714-22.

38. Van de Kerkhove C, Goeminne PC, et al. A cohort description and analysis of the effect of gabapentin on idiopathic cough. Cough 2012;8:9.

39. Ing AJ, Ngu MC, Breslin AB. Pathogenesis of chronic persistent cough associated with gastroesophageal reflux. Am J Respir Crit Care Med 1994;149:160-7. 